\title{
Essential oil and thymol extracted from ajwain as effective antioxidant agents
}

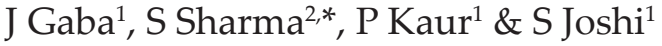 \\ ${ }^{1}$ Department of Chemistry and ${ }^{2}$ Department of Plant Breeding and Genetics, \\ Punjab Agricultural University, Ludhiana-141004, Punjab. \\ *E-mail: sunita_sharma@pau.edu
}

Received 01 November 2019; Revised 04 December 2019; Accepted 05 December 2019

\begin{abstract}
Ajwain is an essential herbal plant with many health and medicinal values. Quantitative phytochemical analysis of ajwain was carried out to determine total phenolic compounds, flavonoids, saponins and tannin content. The phytochemical contents were in the order saponins $>$ tannins $>$ flavonoids > phenolics. Essential oil was extracted and chromatographed for the major constituent thymol which was further characterized with spectral techniques. Further, role of essential oil of ajwain seeds and its major compound thymol for antioxidant activity in respect of total antioxidant capacity and free radical scavenging potential were worked out. Out of thymol and ajwain oil, former was found to be more effective antioxidant at all tested concentrations. Inhibition concentrations $\left(\mathrm{IC}_{50}\right.$ ) of oil, thymol and ascorbic acid were found to be $1.87,1.46$ and 0.01 $\mathrm{mg} \mathrm{mL}^{-1}$, respectively. Results suggest that ajwain and thymol can be used as natural substitutes to synthetic antioxidants in preservation of various food products.
\end{abstract}

Keywords: ajwain, antioxidant, essential oil, phytochemicals, thymol, Trachyspermum ammi

Apiaceae family plants possess a wide range of compounds with numerous biological activities. Trachyspermum ammi L., commonly called ajwain, is a herb from Apiaceae family (Gersbach \& Reddy 2002), originated from Egypt (Boskabady \& Shaikhi 2000). It is widely distributed throughout India, mainly cultivated in Madhya Pradesh, Uttar Pradesh, Maharashtra, Bihar, West Bengal and NorthWestern parts of India. Seeds of ajwain are oval shaped, yellowish-brown to greyish in colour with a wrinkled appearance. In taste, raw seeds are hot and stringent. The seeds have a nutritional composition of carbohydrates
$(24.6 \%)$, fat $(21.1 \%)$, fiber $(11.9 \%)$, protein $(17.1 \%)$, moisture $(8.9 \%)$, flavones, isoflavones, thiamine, riboflavin, nicotinic acid, saponins and other components (7.1\%) including minerals like $\mathrm{Ca}, \mathrm{P}, \mathrm{Fe}, \mathrm{Co}, \mathrm{Cu}$, I and Mn (Ranjan et al. 2012). Brown colored essential oil (2.0 to $4.4 \%$ ) is present in seeds, of which $35-60 \%$ is the strongly antiseptic monoterpene thymol (Gaba et al. 2018). Chatterjee et al. (2013) reported the antioxidant activity of essential oil from ajwain seeds. The present study was conducted to quantify secondary metabolites in ajwain seeds and to compare the antioxidant potential of essential oil and thymol. 
Dried seed sample (500 mg) was refluxed with $10.00 \mathrm{~mL}$ of methanol (80\%) for one hour, filtered and a solution of $50 \mathrm{~mL}$ was prepared by washing with hot water. The resulting solution was used further for quantitative estimation of phytochemicals. Total phenolic content was determined according to Folin-Ciocalteu method (Ebrahimzadeh et al. 2008). Briefly, Folin-Ciocalteu reagent $(1.0 \mathrm{~mL}$ and $2.00 \mathrm{~mL}$ of $2 \% \mathrm{Na}_{2} \mathrm{CO}_{3}$ ) was added to $0.10 \mathrm{~mL}$ of extract. The resulting solution was then allowed to stand for $30 \mathrm{~min}$ at room temperature and the absorbance was read at $765 \mathrm{~nm}$ using UVvisible Spectrophotometer against blank. The phenolic content was estimated by plotting a standard curve of gallic acid and results are presented as milligrams of gallic acid equivalent per gram (mg GAE g ${ }^{-1}$ ). The flavonoid content was adjusted according to Calabro et al. (2004). One hundred microlitres of $10 \% \mathrm{AlCl}_{3}$ and $100 \mathrm{~mL}^{-1}$ of $\mathrm{CH}_{3} \mathrm{COOK}(1 \mathrm{M})$ were added to 0.5 $\mathrm{mL}$ of methanol extract and the volume was adjusted to $5.0 \mathrm{~mL}$ by adding $80 \%$ methanol. The absorbance was measured at $415 \mathrm{~nm}$ using UV-visible spectrophotometer against blank. The quantity of total flavonoids was calculated from the standard curve of quercetin and results are reported as milligrams of quercetin equivalent per gram (mg QE g $\left.{ }^{-1}\right)$. Saponins were determined as per Fenwick \& Oakenfull (1983). Alcohol was removed from the sample by keeping in boiling water bath. After cooling to room temperature, $2 \mathrm{~mL}$ of $\mathrm{CH}_{3} \mathrm{COOC}_{2} \mathrm{H}_{5}$ was added. To this mixture, $1 \mathrm{~mL}$ of reagent $\mathrm{A}$ (0.5 mL anisaldehyde and $99.5 \mathrm{~mL}$ ethylacetate) and $1 \mathrm{~mL}$ of reagent $B$ (concentrated sulphuric acid) were added. Stirred and maintained at ambient temperature for $10 \mathrm{~min}$. The intensity of red color developed was read at $430 \mathrm{~nm}$ in UV visible spectrophoto meter. Saponins was quantified from the standard curve and results were expressed as $\mathrm{mg} \mathrm{SE} \mathrm{g}^{-1} \mathrm{dwb} \pm \mathrm{SD}$. Tannins were determined as per Swain \& Hillis (1959). To $1.00 \mathrm{~mL}$ of extract $8.50 \mathrm{~mL}$ of distilled water was added. To this, $0.50 \mathrm{~mL}$ of Folin Denis reagent was added. After $3 \mathrm{~min}$, saturated solution of $\mathrm{Na}_{2} \mathrm{CO}_{3}(1.00 \mathrm{~mL})$ was added, mixed well and absorbance was measured at $760 \mathrm{~nm}$. The amount of tannins was quantified from the standard curve using tannic acid as standard and results are presented as $\mathrm{mg}^{\mathrm{TAE}} \mathrm{g}^{-1} \mathrm{dwb}$ $\pm \mathrm{SD}$.

In $1 \mathrm{~L}$ round bottom flask, $70 \mathrm{~g}$ of seeds were taken followed by the addition of $700 \mathrm{~mL}$ of distilled water to it. The contents were kept overnight at room temperature and were subjected to hydro-distillation for four hours using a Clevenger type apparatus (Cavalcanti et al. 2004). The extraction of oil was done with diethyl ether and dried over anhydrous sodium sulphate. Extracted essential oil was subjected to GC-MS analysis for determination of chemical composition (Gaba et al. 2018).

The ajwain seed essential oil (5.0 g) was chromatographed over silica gel. Silica gel (600 g), activated at $110^{\circ} \mathrm{C}$ for one hour, with $60-120$ mesh size was used to pack column. Essential oil was dissolved in hexane $(2 \mathrm{~mL})$ and then adsorbed on silica gel for 30 minutes. Column was eluted with hexane and polarity was increased using chloroform. Each fraction was monitored using thin layer chromatography (TLC). Fraction having single compound was subjected to spectral analysis (UV-Visible, IR, ${ }^{1} \mathrm{H}$ NMR and ${ }^{13} \mathrm{C}$ NMR) for characterization of the compound. UV spectra was recorded on UV 2600 spectrophotometer (Techcomp company), IR spectra (Perkin-Elmer) using Model RX-1 FTIR Spectrophotometer. ${ }^{1} \mathrm{H}-\mathrm{NMR}$ and ${ }^{13} \mathrm{C}-\mathrm{NMR}$ spectra were recorded on Bruker Avance II 400 $\mathrm{MHz}$ spectrophotometer using tetra methyl silane as internal reference. The melting point of thymol was determined in open capillaries.

The essential oil of ajwain and thymol were evaluated for antioxidant activity in terms of total antioxidant capacity (TAC) and free radical scavenging activity (RSA) using dimethyl sulfoxide (DMSO) as control and ascorbic acid as standard. Total antioxidant capacity was evaluated by phosphomolybdenum complex formation method (Prieto et al. 1999). The assay is based on the reduction of Mo (VI)-Mo (V) by the extract and subsequent formation of a green phosphate/Mo (V) complex at acidic $\mathrm{pH}$. Three milliliters of test compound was combined with 
$1 \mathrm{~mL}$ of reagent solution $(0.60 \mathrm{M}$ sulfuric acid, 28 $\mathrm{mM}$ sodium phosphate and $4 \mathrm{mM}$ ammonium molybdate). In case of blank, $3 \mathrm{~mL}$ of DMSO was used in place of samples. The tubes containing the reaction solution were capped and incubated in a boiling water bath at $95^{\circ} \mathrm{C}$ for $90 \mathrm{~min}$. After cooling to room temperature, the absorbance of the solution was measured at $695 \mathrm{~nm}$ using a Spectrophotometer. The antioxidant capacity is presented as ascorbic acid equivalent using the following linear equation established using ascorbic acid as standard:

$$
\left[A=0.016 C-0.03 ; R^{2}=0.990\right]
$$

Where, $\mathrm{A}$ is absorbance at $695 \mathrm{~nm}$ and $\mathrm{C}$ is concentration as ascorbic acid equivalent $(\mu \mathrm{g}$ $\mathrm{mg}^{-1}$ )

The free radical scavenging activity of the compounds was estimated by their capacity to bleach the stable radical 2,2-diphenyl-1picrylhydrazyl (DPPH), as reported (Blois 1958). DPPH gives a strong absorption band at $517 \mathrm{~nm}$ in the visible region because of its odd electronic structure. Different concentrations $(3.00,2.00$, $1.00,0.50,0.25,0.10,0.05$ and $0.025 \mathrm{mg} \mathrm{mL}^{-1}$ ) of test compounds $(40 \mathrm{~mL})$ and ascorbic acid $(40 \mathrm{~mL})$, dissolved in methanol, were added to $3.96 \mathrm{~mL}$ of the DPPH solution. After $30 \mathrm{~min}$, the absorbance was read at $517 \mathrm{~nm}$ at room temperature, and the scavenging activity was calculated as percentage of the radical reduction. Each experiment was executed thrice. Methanol was used as control and ascorbic acid was used as standard. The radical scavenging activity was obtained as follows:

$$
\begin{aligned}
& \text { Radical Scavenging Activity }(\%)= \\
& {\left[\left(\mathrm{A}_{\text {control }}-\mathrm{A}_{\text {sample }}\right) / \mathrm{A}_{\text {control }}\right] \times 100}
\end{aligned}
$$

Where $\mathrm{A}_{\text {control }}$ and $\mathrm{A}_{\text {sample }}$ are the absorbances of blank (methanol) and test compounds, respectively at $517 \mathrm{~nm}$. $\mathrm{IC}_{50}$ values were also calculated.

The Factorial CRD design anaylsis was followed and $C D$ values were calculated.

The total phenolic content (TPC) in methanolic extracts of ajwain seeds is presented in Table
1. The amount of total phenols was found to be $3.40 \pm 0.049 \mathrm{mg} \mathrm{GAE} \mathrm{g}^{-1} \mathrm{dwb}$ (Table 1). Similar results were obtained by Ishiaque et al. (2013) and Aafreen et al. (2017). Phenolic compounds have oxidants and play a significant function in absorbing and neutralizing free radicals, quenching singlet and triplet oxygen or degrading peroxides (Yingming et al. 2004; Soobrattee 2005). Plant flavonoids have in vitro as well as in vivo antioxidant activity (Shimoi et al. 1996). It is considered that the antioxidant activity of flavonoid compounds was due to their scavenging or chelating process (Cook \& Samman 1996). The amount of flavonoids found in ajwain seeds was $7.40 \pm$ $0.062 \mathrm{mg} \mathrm{QE} \mathrm{g}^{-1} \mathrm{dwb}$ (Table 1). Similar result on total flavonoids content was observed by Tacouri et al. (2013).

Saponin and tannin contents of ajwain seeds were $47.19 \pm 0.035 \mathrm{mg} \mathrm{SE} \mathrm{g}^{-1} \mathrm{dwb}$ and $11.26 \pm$ $0.052 \mathrm{mg}^{\mathrm{TAE}} \mathrm{g}^{-1} \mathrm{dwb}$, respectively (Table 1). Saponins are glucosides with foaming attributes. These have a polycyclic aglycones attached to one or more sugar side chains and possess wide range of biological activities viz., antifungal, antioxidant etc. (Milgate \& Roberts 1995). Tannins are polyphenolic plant metabolites with biological role related to protection against infections or insects and herbivores attacks (Khanbabaee \& Van Ree 2001). Among the different phytochemicals, saponin registered highest content followed by tannins, total flavonoids and total phenolics in ajwain seeds (Table 1).

Table 1. Quantitative estimation of phytochemicals in ajwain seeds

\begin{tabular}{cc}
\hline Phytochemical & Amount $^{\mathrm{a}-\mathrm{d}}$ \\
\hline Total Phenolic $^{\mathrm{a}}$ & $3.40 \pm 0.049$ \\
Total Flavonoids $^{\mathrm{b}}$ & $7.40 \pm 0.062$ \\
Saponins $^{\mathrm{c}}$ & $47.19 \pm 0.035$ \\
Tannins $^{\mathrm{d}}$ & $11.26 \pm 0.052$ \\
\hline
\end{tabular}

Data are presented as mean \pm standard deviation ${ }^{\mathrm{a}} \mathrm{mg}$ gallic acid equivalent $\mathrm{g}^{-1} \mathrm{dwb} \pm \mathrm{SD} ;{ }^{\mathrm{b}} \mathrm{mg}$ quercetin equivalent $\mathrm{g}^{-1} \mathrm{dwb} \pm \mathrm{SD}$; ${ }^{\mathrm{c}} \mathrm{mg}$ saponin equivalent $\mathrm{g}^{-1} \mathrm{dwb} \pm \mathrm{SD} ;{ }^{\mathrm{d}} \mathrm{mg}$ tannic acid equivalent $\mathrm{g}^{-1} \mathrm{dwb} \pm \mathrm{SD} ; \mathrm{dwb}$ : dry weight basis. 
Yield of ajwain oil obtained was $1.71 \%$. It was pale yellow liquid having refractive index of 1.409. It was insoluble in water and completely soluble in organic solvents such as hexane, benzene, chloroform, diethyl ether, methanol and acetone. TLC of essential oil showed four coloured spots having $R_{\mathrm{f}}$ values of 0.48 (yellowish-brown), 0.71 (purple-pink), 0.78 (brown) and 0.94 (brown). The $R_{f}$ value of thymol was 0.71 which confirmed its presence in essential oil. The results are in accordance with Saini et al. (2014). Major compound of ajwain oil was found to be thymol $(72.03 \%)$ in GC-MS analysis (Gaba et al. 2018). Percentage of thymol was 43.7 in ajwain seeds as reported by Nickavara et al. (2014).

Fraction 3 of ajwain seed essential oil chromatographed over silica gel was identified as thymol on the basis of melting point and spectroscopic analysis (Table 2). The melting point was found to be $48-49^{\circ} \mathrm{C}$. In UV-visible spectroscopy, thymol absorbed at $275 \mathrm{~nm}$. IR $\left(\mathrm{KBr}, \mathrm{v}, \mathrm{cm}^{-1}\right)$ spectrum exhibited prominent peaks at 3222 (OH stretching), 3035 (aromatic C-H stretching), $2962\left(v_{\text {as }} \mathrm{CH}_{3}\right.$ stretching), $2869\left(v_{\text {sym }} \mathrm{CH}_{3}\right.$ stretching), 1619, 1584, 1516 and 1426 (aromatic $C=C$ stretching), 1456 ( $v_{\text {as }}$ CHbending), 1359 (C-H bending of gemdimethyl), 1249 (C-O stretching), 943 and 803 ( $\mathrm{CH}$ bending), 735 (C-C bending). ${ }^{1} \mathrm{H}$ NMR spectrum $\left(\mathrm{CDCl}_{3}{ }^{\prime}\right.$ ' $\delta$ ', ppm) of thymol showed a doublet of six protons (attached to $\mathrm{C}_{9}$ and $\mathrm{C}_{10}$ ) in the range of $1.22-1.24(J=6.88 \mathrm{~Hz})$. A singlet at 2.25 was recorded due to three protons with $C_{7}$. A multiplet due to hydrogen at $\mathrm{C}_{8}$ was recorded in the range of 3.12-3.19. Peak corresponding to $\mathrm{OH}$ group of thymol was observed as singlet at 4.73. Proton attached to $\mathrm{C}_{2}$ appeared as singlet at 6.54 whereas protons at $C_{5}$ and $C_{6}$ were observed as doublets at $6.71-6.73(J=7.72 \mathrm{~Hz})$ and 7.06$7.08(J=7.76 \mathrm{~Hz})$, respectively (Fig. 1). Similar ${ }^{1} \mathrm{H}$ NMR peaks were observed by Mulinacci et al. (1996). ${ }^{13} \mathrm{C}$ NMR spectrum $\left(\mathrm{CDCl}_{3^{\prime}}\right.$ ' $\delta$ ', ppm) recorded a peak at 24.24 due to $\mathrm{C}_{9}$ and $\mathrm{C}_{10}$. Peaks corresponding to $C_{7}$ and $C_{8}$ appeared at 23.76 and 26.16, respectively. Five aromatic carbons $\left(\mathrm{C}_{1}, \mathrm{C}_{2}, \mathrm{C}_{4}, \mathrm{C}_{5}\right.$ and $\left.\mathrm{C}_{6}\right)$ were registered at 114.26,
Table 2. Different fractions of essential oil after column chromatography

\begin{tabular}{|c|c|c|c|}
\hline $\begin{array}{l}\text { S. } \\
\text { No. }\end{array}$ & Eluent (ml) & $\begin{array}{l}\text { Weight } \\
(\mathrm{g})\end{array}$ & $\begin{array}{c}\text { Observations } \\
\text { from TLC }\end{array}$ \\
\hline 1. & $\begin{array}{c}\text { Hexane }(12 \times \\
100)\end{array}$ & 1.32 & Mixture \\
\hline 2. & $\begin{array}{c}\text { Hexane: } \\
\text { Chloroform } \\
(95: 5) \\
(8 \times 100)\end{array}$ & 0.64 & Mixture \\
\hline 3. & $\begin{array}{c}\text { Hexane: } \\
\text { Chloroform }(9: 1) \\
\qquad(8 \times 100)\end{array}$ & 2.35 & $\begin{array}{l}\text { Pure } \\
\text { crystalline } \\
\text { thymol, } \\
\text { m.pt. } 48-49 \\
{ }^{0} \mathrm{C}\end{array}$ \\
\hline 4. & $\begin{array}{c}\text { Hexane: } \\
\text { Chloroform } \\
(85: 15) \\
(12 \times 100)\end{array}$ & 0.69 & Mixture \\
\hline
\end{tabular}

121.35, 127.53, 135.43 and 137.13. Aromatic carbon $\mathrm{C}_{3}$ having $\mathrm{OH}$ group attached to it was recorded at 153.51.

Essential oil and major compound (thymol) of ajwain were evaluated for antioxidant activity in terms of total antioxidant capacity (TAC) and free radical scavenging activity (RSA) using dimethyl sulfoxide (DMSO) as control and ascorbic acid as standard. Total antioxidant capacity was assessed by reduction of Mo (VI) to Mo (V) as ascorbic acid equivalents. None of the tested natural products were found to have absorbance more than control at $695 \mathrm{~nm}$.

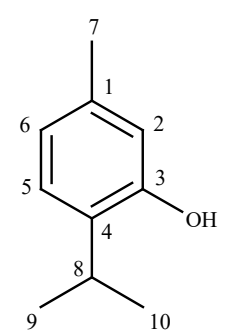

Fig. 1. Thymol 
Therefore, it may be concluded that ajwain oil and thymol do not act as antioxidants by reduction mechanism. It may be due to less stability/antiaromatic character of oxidized form of thymol. The free radical scavenging activity was determined using DPPH as substrate. The radical scavenging efficiency of the oil and thymol was expressed in terms of $\mathrm{IC}_{50}$ values (Fig. 2).

Out of thymol and ajwain oil, former was found to be more effective at all the tested concentrations. Therefore, phenolic compound (thymol) may be responsible for the antioxidant activity of ajwain seeds. Electron donating

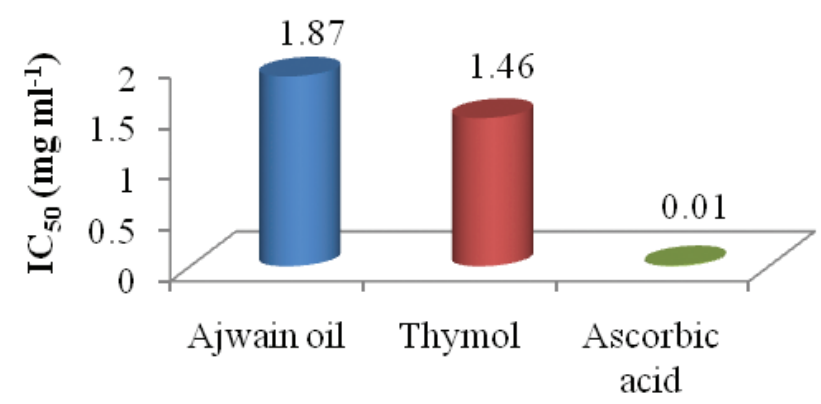

Treatments

Fig. 2. DPPH free radical scavenging activity $\left(\mathrm{IC}_{50}\right.$ values) of ajwain oil and thymol

isopropyl and methyl groups at ortho and meta position with respect to hydroxyl group increase the stabilization of the radical, making it a better radical scavenger. Also, redox properties of phenolic compounds help in absorption, neutralization and quenching of peroxides, contributing towards the strong antioxidant activities (Jamuna et al. 2017). Per cent RSA varied directly with concentration of both oil

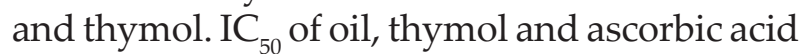
were found to be 1.87, 1.46 and $0.01 \mathrm{mg} \mathrm{mL}^{-1}$, respectively. Gandomi et al. (2014) also assessed the antioxidant potential of ajwain essential oil and recorded similar results. Both ajwain oil and thymol registered less per cent RSA than ascorbic acid at all the concentrations.

Presence of various phytochemicals in ajwain seeds may confer many pharmacological benefits. Due to lower $\mathrm{IC}_{50}$ value of thymol as compared to essential oil, the antioxidant property of ajwain may be ascribed to the presence of thymol in it.

\section{Acknowledgements}

This study was funded by Innovation in Science Pursuit for Inspired Research (INSPIRE), Department of Science and Technology (DST), Government of India. The Authors are thankful to Sophisticated Analytical Instrumentation Facility (SAIF), Punjab University, Chandigarh for providing $\mathrm{IR},{ }^{1} \mathrm{H} \mathrm{NMR}$ and ${ }^{13} \mathrm{C} \mathrm{NMR}$ spectrum analysis facility.

\section{References}

Aafreen S, Khan Z H, Damodar K, Khan N D \& Mular S M 2017 Phytochemical screening and total phenolic content of kalonji and ajwain seeds. Int. J. Appl. Res. 3: 565-568.

Blois M S 1958 Antioxidant determinations by the use of a stable free radical. Nature 181: 1199-1200.

Boskabady M H \& Shaikhi J 2000 Inhibitory effect of Carum copticum on histamine $\left(\mathrm{H}_{1}\right)$ receptors of isolated guinea-pig tracheal chains. J. Ethnopharmacol. 69: 217-227.

Calabro M L, Galtieri V, Cutroneo P, Tommasini S, Ficarra P \& Ficarra R 2004 Study of the extraction procedure by experimental design and validation of a LC method for determination of flavonoids in Citrus bergamia juice. J. Pharm. Biomed. Anal. 35: 349-363.

Cavalcanti E S B, Morais S M, Lima M A A \& Santana E W P 2004 Larvicidal activity of essential oils from Brazilian plants against Aedes aegypti L. Mem. Inst. Oswaldo. Cruz. 99: 541-544.

Chatterjee S, Goswami N \& Kothari N 2013 Evaluation of antioxidant activity of essential oil from Ajwain (Trachyspermum ammi) seeds. Int. J. Green Pharm. 7: 140-144.

Cook N C \& Samman S 1996 Flavonoids: Chemistry, metabolism, cardio protective effects and dietary sources. J. Nutr. Biochem. 7: 66-76.

Ebrahimzadeh M A, Pourmorad F \& Hafezi S 2008 Antioxidant activities of Iranian corn silk. 
Turk. J. Biol. 32: 43-49.

Fenwick D E \& Oakenfull D 1983 Saponin content of food plants and some prepared foods. J. Sci. Food. Agric. 34: 186-191.

Gaba J, Sharma S, Joshi S \& Gill P 2018 Gas chromatography-Mass spectrometric analysis of essential oil, nutritional and phytochemical composition of ajwain seeds (Trachyspermum ammi L.). J. Essent. Oil Bear. Pl. 21: 1128-1137.

Gandomi H, Abbaszadeh S, Jebellijavan A \& Sharifzadeh A 2014 Chemical constituents, antimicrobial and antioxidative effects of Trachyspermum ammi essential oil. J. Food. Process. Pres. 38: 1690-1695.

Gersbach P V \& Reddy N 2002 Non-invasive localization of thymol accumulation in Carum copticum (Apiaceae) fruits by chemical shift selective magnetic resonance imaging. Ann. Bot. 90: 253-257.

Ishtiaque S, Khan N, Siddiqui M A, Siddiqi R \& Naz S 2013Antioxidant potential of the extracts, fractions and oils derived from oilseeds. Antioxidants 2: 246-256.

Jamuna S, Sadullah M S S, Ashokkumar R, Shanmuganathan G, Mozhib S S \& Devaraj S N 2017 Potential antioxidant and cytoprotective effects of essential oil extracted from Cymbopogon citratus on OxLDL and $\mathrm{H}_{2} \mathrm{O}_{2}$ LDL induced human peripheral blood mononuclear cells (PBMC). Food Sci. Hum. Wellness 6: 60-69.

Khanbabaee K\& van Ree T 2001 Tannins: Classification and definition. Nat. Prod. Rep. 385: 641-649.

Milgate J \& Roberts D C K 1995 The nutritional and biological significance of saponins. Nutr. Res. 15: 1223-1249.

Mulinacci N, Melani F, Vincieri F F, Mazzi G \& Romani A $1996{ }^{1} \mathrm{H}-\mathrm{NMR}$ NOE and molecular modelling to characterize thymol and carvacrol $\beta$-cyclodextrin complexes. Int. J. Pharm. 128: 81-88.

Nickavara B, Adelia A \& Nickavarb A 2014 TLCBioautography and GC-MS analyses for detection and identification of antioxidant constituents of Trachyspermum copticum essential oil. Iran J. Pharm. 13: 127-133.

Prieto P, Pineda M \& Aguilar M 1999 Spectrophotometric quantitation of antioxidant capacity through the formation of a phosphomolybdenum complex: Specific application to the determination of vitamin E. Anal. Biochem. 269: 337-341.

Ranjan B, Manmohan S, Singh S R \& Singh R B 2012 Medicinal uses of Trachyspermum ammi: A review. Phcog. Rev. 6: 56-60.

Shaheen F A 2014 Critical temperature change as important factor of Callosobruchus chinensis L. management in chickpea grains. Asian. J. Agric. Biol. 2: 258-262.

Shimoi K, Masuda S, Shen B, Furugori M \& Kinae N 1996 Radioprotective effects of antioxidative plant flavonoids in mice. Mutat. Res. 350: 153-161.

Soobrattee M A, Neergheen V S, Luximon-Ramma A, Aruoma O I \& Bahorun OT 2005 Phenolics as potential antioxidant therapeutic agents: Mechanism and actions. Mutat. Res. Fund. Mol. 579: 200-213.

Swain J \& Hillis E 1959 The phenolic constituents of Prunus domestica. The quantitative analysis of phenolic constituents. J. Sci. Food Agri. 10: 63-68.

Tacouri D D, Baboolall D R \& Puchooa D 2013 In vitro bioactivity and phytochemical screening of selected spices used in Mauritian foods. Asian Pac. J. Trop. Dis. 3: 253-261.

Yingming P, Ping L, Hengshan W \& Min L 2004 Antioxidant activities of several chinese medicinal herbs. Food Chem. 88: 347-350. 